\title{
Pattern of Brain Injury in the Acute Setting of Human Septic Shock
}

\author{
Andrea Polito ${ }^{1}$, Frédéric Eischwald ${ }^{2}$, Anne-Laure Le Maho ${ }^{1}$, Angelo Polito ${ }^{3}$,Eric Azabou ${ }^{4}$, Djillali Annane ${ }^{1}$, \\ Fabrice Chrétien ${ }^{5}$, Robert D Stevens ${ }^{6}$, Robert Carlier $^{2}$ and Tarek Sharshar ${ }^{1 *}$
}

\begin{abstract}
Background: Sepsis-associated brain dysfunction has been linked to white matter lesions (leukoencephalopathy) and ischemic stroke. Our objective was to assess the prevalence of brain lesions in septic shock patients requiring magnetic resonance imaging (MRI) for an acute neurologic change.

Method: 71 septic shock patients were included in a prospective observational study. Patients underwent daily neurological examination. Brain MRI was obtained in patients who developed focal neurological deficit, seizure, coma, or delirium. Electroencephalogy was performed in case of coma, delirium, or seizure. Leukoencephalopathy was graded and considered present when white matter lesions were either confluent or diffuse. Patient outcome was evaluated at 6 months with the Glasgow Outcome Scale (GOS).

Results: We included 71 patients with median age of 65 years (56 to 76) and SAPS II at admission of 49 (38 to 60). MRI was indicated on focal neurological sign in 13 (18\%), seizure in 7 (10\%), coma in 33 (46\%), and delirium in 35 (49\%). MRI was normal in 37 patients (52\%) and showed cerebral infarcts in 21 (29\%), leukoencephalopathy in 15 $(21 \%)$, and mixed lesions in 6 (8\%). EEG malignant pattern was more frequent in patients with ischemic stroke or leukoencephalopathy. Ischemic stroke was independently associated with disseminated intravascular coagulation (DIC), focal neurologic signs, increased mortality, and worse GOS at 6 months.
\end{abstract}

Conclusions: Brain MRI in septic shock patients who developed acute brain dysfunction can reveal leukoencephalopathy and ischemic stroke, which is associated with DIC and increased mortality.

\section{Introduction}

Brain dysfunction is a frequent and severe complication of septic shock, as it occurs in up to $60 \%$ of patients $[1,2]$ and is associated with increased mortality [3] and long-term cognitive impairment $[4,5]$. It is clinically characterized by an acute alteration of consciousness, ranging from coma to delirium, and less frequently by seizures or focal neurologic signs $[1,6]$. The neuroradiologic correlates of these symptoms are poorly known, as few imaging studies have been carried out in septic-shock patients. In a preliminary study of nine septic-shock patients who underwent a brain MRI because of an acute neurologic alteration, we found ischemic stroke and confluent or diffuse white matter lesions (which we called leukoencephalopathy) in two and

\footnotetext{
* Correspondence: tarek.sharshar@rpc.aphp.fr

'General Intensive Care Medicine, Assistance Publique Hôpitaux de Paris, Boulevard Raymond Poincaré Hospital, University of Versailles Saint-Quentin en Yvelines, Raymond Poincaré 104, Garches, 92380, France

Full list of author information is available at the end of the article
}

five patients, respectively [7]. These findings provided insight into the pathophysiology of sepsis-related brain dysfunction. The demonstration of ischemia suggests the importance of cerebral perfusion impairment and microcirculatory dysfunction, whereas leukoencephalopathy is indicative of a range of pathologic processes including impairment of the blood-brain barrier, axon loss, gliosis, dilated perivascular spaces, and lacunar infarcts $[1,7]$. Recently, one group reported abnormalities on brain imaging in two-thirds of 64 critically ill patients who developed acute neurologic changes [8]. However, only a small proportion of these patients were septic, and brain imaging was predominantly obtained by CT scan instead of MRI.

Our aim was to assess the prevalence of ischemic stroke and leukoencephalopathy and to identify their association with predisposing factors, clinical manifestations, and outcome in a cohort of septic-shock patients with acute clinical signs of brain dysfunction. It was not
Ciomed Central 
ethically conceivable to perform an MRI in septic-shock patients without neurological symptoms because of the risk of transport.

\section{Materials and methods \\ Patients and settings}

This was a prospective observational study that was conducted in an 18-bed medical and surgical intensive care unit (ICU) of a university teaching hospital (Raymond Poincaré Hospital, Garches, France). Patients were enrolled at our institution from November 2005 to June 2012. Patients were eligible for inclusion if they met the following criteria: (a) septic shock defined according to established criteria [9], and (b) evidence of acute brain dysfunction defined as the presence of any of the following: coma, delirium, focal neurologic deficit, or seizure (defined subsequently). Patients were excluded if they had any preexisting central nervous system disease (neurodegenerative, inflammatory, and cerebrovascular disease), unstable respiratory and hemodynamic status, or contraindications to MRI. Elderly patients (older than 80 years) were not included because of the high prevalence of pre-existing white matter disease in this population. Patients with brain infection and endocarditis were excluded. The study was approved by the ethics committee of Saint-Germainen-Laye, and informed consent was obtained from patients' closest relatives $[10,11]$. The study protocol was approved by the local institutional review board, and oral informed consent was obtained from the patients' closest relatives and recorded in the patient's medical record.

\section{Neurologic examination}

Neurologic examination was performed daily by a senior neurologist (TS) and included (a) assessment of level of consciousness by using the motor and eye responses of the GCS; (b) assessment of agitation by using either the ATICE scale [12] or RASS [13]; (c) assessment of delirium by using CAM-ICU [14]; (d) cranial nerve examination, that is, pupillary size (miosis, normal, or mydriasis) and response to light, and evaluation of grimace; in comatose or sedated patients assessment included resting eye position (normal or abnormal), spontaneous eye movement (present or absent), blink response to strong light, corneal reflexes, grimacing in response to retromandibular pressure, oculocephalic reflex, and cough reflex after tracheal suctioning; and e) patellar and bicipital deep tendon reflexes and plantar reflexes. Coma was defined as GCS $<8$ in non-sedated patients or after 3 days of discontinuation of sedation in previously sedated patients [15]. Seizures were defined as generalized or focal (face or limb) tonic or clonic movement or recurrent twitching of one limb or eyelid twitching. Any lateralized deficit was considered a focal neurological deficit.

\section{Brain magnetic resonance imaging}

Vital signs including blood pressure, electrocardiogram (ECG), and pulse oximetry were monitored continuously during MRI (Maglife Bruker MR compatible monitoring), as described elsewhere [7]. The duration of MRI examination ranged from 30 to 45 minutes. None of the patients experienced physiological or neurological deterioration during MRI procedures or during transport.

MRI was performed on a 1.5-T scanner (Intera; Philips, Eindhoven, The Netherlands) and included sagittal gradient echo $\mathrm{T}_{1}$-weighted, axial turbo spin echo with fluidattenuated inversion recovery (FLAIR), $\mathrm{T}_{2}$-weighted, and axial echo-planar imaging (EPI) diffusion-weighted imaging sequences. All axial images were acquired parallel to the neuroophthalmic plane. Diffusion-weighted imaging (DWI) was performed with diffusion gradients applied along three orthogonal axes and a b factor of $1,000 \mathrm{~ms}$. Data obtained from these images were used to construct isotropic DWI images and apparent diffusion coefficient (ADC) maps. Other imaging included $\mathrm{T}_{1}$-weighted imaging with contrast injection (Gadoterate meglumine, Gado dota, DOTAREM; Guerbet Laboratory, Aulnaysous-Bois, France; $0.1 \mathrm{mmol} / \mathrm{kg}$ ), and with magnetization transfer contrast (MTC), time-of-flight MR angiography, and perfusion imaging. This MRI protocol was designed to maximize sensitivity to hemorrhage, ischemic stroke, and white matter lesions (that is, leukoencephalopathy).

MRI results were categorized as normal or abnormal. In contrast to our previous report, we classified white matter lesions as significant when patchy, confluent, or diffuse. Punctiform white matter lesions were considered not pathologic.

\section{Brain complementary investigations}

In patients with ischemic stroke, a standard ECG, an echocardiography, and a carotid Doppler were performed. In patients with arrhythmias, continuous electrocardiographic monitoring (Spacelabs Health Care, Ultraview SL, Washington, DC, USA) was also performed. According to Toast classification, patients were eventually classified as either having or not cardioembolic and/or atherosclerosis (thromboembolic) episode [16]. All patients who showed clinical signs of coma, delirium, or seizure underwent EEG examination. Every EEG received a score between 0 and 5 by a senior neurophysiologist (EA) and classified according to Synek score as benign (grade 0 to 2), uncertain (grade 3), or malignant (grades 4 and 5) [17].

\section{Definition of variables and outcomes}

Demographic characteristics, known risk factors for cardiovascular disease (that is, smoking, hypertension, coronary artery disease, diabetes, hypercholesterolemia, hypertriglyceridemia, and stroke), estimated prognosis of pre-existing 
underlying illness (graded as nonfatal, ultimately, and rapidly fatal disease), date and category of admission (medical or surgical) in the ICU, SAPS-II as well as microbiological data were recorded at admission. From admission to the day of MRI, SOFA score, vital signs, type and dose of catecholamine infused, sedatives, analgesics and antibiotics, use of steroids, days of mechanical ventilation, and standard laboratory tests were recorded daily. Hypotension was defined as a mean arterial pressure $<60 \mathrm{~mm}$ $\mathrm{Hg}$; oxygen desaturation was defined as an $\mathrm{SaO}_{2}<90 \%$. The duration (days) of catecholamines infusion, maximum and minimum systolic and mean blood pressure, time (hours) spent with MBP $<60 \mathrm{~mm} \mathrm{Hg}$ or with $\mathrm{SaO}_{2}<90 \%$, and maximal SOFA score were also recorded. According to the International Society of Thrombosis and Haemostasis, DIC was defined as a score based on alteration of routine coagulation tests (platelet count, fibrin and fibrinogen levels, prothrombin time) more than 5 [18].

The primary outcome variable was the presence of MRI signs of ischemic stroke and leukoencephalopathy in patients with septic shock and acute brain dysfunction. Secondary outcomes were represented by ICU mortality, hospital and ICU length of stay, duration of mechanical ventilation, and GOS at 6 months (dichotomized at $\leq 3$ versus $>3$ ) [19].

\section{Statistical analysis}

STATA software, Version 11.1 data analysis and statistical software (StataCorp LP, College Station, TX, USA) was used for statistical analysis. Continuous variables are reported as median ( $10^{\text {th }}$ and $90^{\text {th }}$ percentiles) and as number (proportion) for categoric variables. KruskalWallis and $\chi^{2} /$ Fisher Exact tests were used to determine unadjusted association between type of brain lesions and continuous and categoric variables, respectively. Additional multivariable analysis was performed by means of logistic regression to seek adjusted relations between type of brain lesions and ICU mortality and GOS at 6 months.

The selection of independent variables for the model was based on statistical significance at univariable testing. Covariates with a value of $P<0.05$ were included in the multivariable analysis. The limit for statistical significance was set at $P=0.05$. All tests were two-sided. The authors had full access to and take full responsibility for the integrity of the data. All authors have read and agree to the manuscript as written.

\section{Results}

From November 2005 to June 2012, 170 patients were admitted for septic shock and developed acute brain dysfunction; of those, 71 (42\%) patients were enrolled and underwent brain MRI, with a median time delay from acute brain dysfunction of three days. 57 (33\%) patients were not enrolled because of patient's death before MRI $(n=40)$ or MRI contraindication $(n=17)$ whereas 42 (25\%) were excluded from the study because of a prior central nervous system disorder, endocarditis, or age older than 80 years. CT scan was performed in $12(17 \%)$ (Figure 1).

\section{Patients' characteristics, neuroimaging, and outcome}

Patients' characteristics are presented in Table 1. Coma was present in 33 (46\%) cases, delirium in 35 (49\%), focal neurologic deficit in $13(18 \%)$, and seizure in seven (10\%). Mixed neurologic deficits, defined as more than one neurological sign in the same patient, were present in 16 (23\%) patients. MRI was normal in $37(52 \%)$ patients. In $21(29 \%)$ patients, MRI demonstrated evidence of ischemic stroke, whereas leukoencephalopathy was found in 15 (21\%; Figure 2). Ischemic strokes were large in nine (43\%) patients, multiple in 14 (67\%) patients Figures 3 and 4), and junctional in six (29\%) patients. Cardiovascular investigations evidenced a cardioembolic factor in six patients, a thromboembolic factor in eight, both in two, and none in two. They were incomplete in five patients, among whom three died rapidly. Six (8\%) patients had more than one type of brain lesion at MRI. Neurologic symptoms and MRI findings did not change over the study period.

Among patients who developed only coma, delirium, or both, EEG was performed in 47 (92\%) of 51 patients. Coma was associated with median EEG grade of 3.5 (3.0 to 4.0 ), and delirium with 3.0 (1.0 to 3.5). EEG grade $>3$ (malignant pattern) was significantly more frequent in patients who died (11 (69\%) versus five $(16 \%) ; P=0.001)$ (Table 2).

A comparison of patients with normal MRI $(n=37)$, isolated ischemic stroke $(n=16)$, and isolated

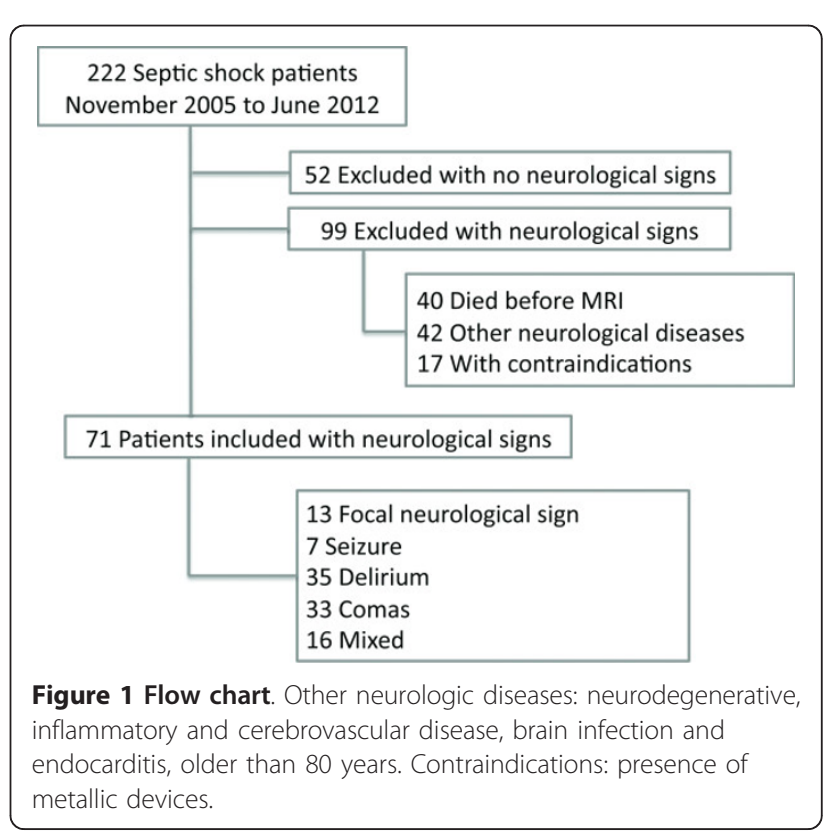


Table 1 Main characteristics between admission, inclusion, and after hospital discharge

\begin{tabular}{|c|c|}
\hline Variables & $N=71$ \\
\hline \multicolumn{2}{|l|}{ Admission } \\
\hline Women & $27(38)$ \\
\hline Age (years) & $65(56-76)$ \\
\hline $\begin{array}{l}\text { Cardiovascular risk factors (\%) } \\
\text { Atrial fibrillation (\%) }\end{array}$ & $\begin{array}{l}40(56) \\
11(16)\end{array}$ \\
\hline Blood culture (\%) & $17(24)$ \\
\hline Pneumonia & $42(59)$ \\
\hline \multicolumn{2}{|l|}{ Pathogens } \\
\hline Pure Gram negative & $28(39)$ \\
\hline Pure Gram positive & $16(23)$ \\
\hline SAPS II at admission & $49(38-60)$ \\
\hline Knaus (B or more) & $56(79)$ \\
\hline Mac Cabe $(>1)$ & $29(41)$ \\
\hline \multicolumn{2}{|l|}{ Admission to MRI } \\
\hline Delay from admission to MRI (days) & $7(2-10)$ \\
\hline Delay from neurologic signs to MRI (days) & $3(1-5)$ \\
\hline Highest SOFA (from 0 to 24) & $13(9-16)$ \\
\hline Highest neurologic SOFA score (from 0 to 4) & $4(2-4)$ \\
\hline Highest respiratory SOFA score (from 0 to 4) & $3(2-3)$ \\
\hline Highest cardiovascular SOFA score (from 0 to 4 ) & $3(3-4)$ \\
\hline Cumulative time with MBP $<60 \mathrm{~mm} \mathrm{Hg}$ (hours) & $5(2-8)$ \\
\hline Highest hepatic SOFA score (from 0 to 4) & $1(0-2)$ \\
\hline Highest renal SOFA score (from 0 to 4) & $1(0-2)$ \\
\hline Presence of DIC (\%) & $34(48)$ \\
\hline $\begin{array}{l}\text { Highest coagulation SOFA score (from } 0 \\
\text { to 4) }\end{array}$ & $2(0-3)$ \\
\hline Lowest/highest plasma sodium level (mM) & $\begin{array}{c}134(129-136) / 144 \\
(140-148)\end{array}$ \\
\hline Lowest/highest plasma glucose level (mM) & $\begin{array}{c}4.6(3.6-5.1) / 12.5 \\
\quad(10.0-16.9)\end{array}$ \\
\hline Highest plasma lactate level (mM) & $4.3(2.4-6.0)$ \\
\hline Lowest plasma platelets level $\left(10^{9} / \mathrm{L}\right)$ & $96(45-220)$ \\
\hline Time on vasopressors (days) & $4(2-8)$ \\
\hline $\begin{array}{l}\text { Mean (nor)epinephrine infusion rate } \\
(\mu \mathrm{g} / \mathrm{kg} / \mathrm{min})\end{array}$ & $0.83(0.71-1.62)$ \\
\hline Insulin therapy (\%) & $59(83)$ \\
\hline $\begin{array}{l}\text { Sedation (\%) } \\
\text { Mean midazolam infusion rate (mg/h) }\end{array}$ & $\begin{array}{c}49(69) \\
7.3(5.1-9.0)\end{array}$ \\
\hline Duration of sedation (days) & $2(0-5)$ \\
\hline \multicolumn{2}{|l|}{ After MRI } \\
\hline Length of mechanical ventilation (days) & $21(6-45)$ \\
\hline Length of stay in the ICU (days) & $31(14-53)$ \\
\hline Mortality & $23(32)$ \\
\hline GOS at 6 months $>3(\%)$ & $37(52)$ \\
\hline
\end{tabular}

Data are expressed in number (\%) or median (IQR). SAPS-II, New Simplified Acute Physiology Score; MRI, magnetic resonance imaging; SOFA, Sepsis-related Organ Failure Assessment; $\mathrm{PaO}_{2}$, partial pressure of oxygen in arterial blood; $\mathrm{SaO}_{2}$, oxygen saturation; $\mathrm{MBP}$, mean blood pressure; DIC, disseminated intravascular coagulation; ICU, intensive care unit; GOS, Glasgow Outcome Scale leukoencephalopathy $(n=10)$ is presented in Table 3. Age, preexisting cardiovascular risk factors, severity of septic shock, and hemodynamic failure were not significantly different among these subgroups (Table 2), as well as pathogens, vasopressors, $\mathrm{PaO}_{2} / \mathrm{FiO}_{2}$ ratio, minimal $\mathrm{SpO}_{2}$, prothrombin time, and hemoglobin and lactate levels (data not shown). Focal neurologic deficits were more frequently associated with ischemic stroke (Table 3). Among the 47 patients who underwent an EEG, four had mixed brain lesions, and EEG grade $>3$ (malignant pattern) was more frequent in patients with isolated ischemic stroke or isolated leukoencephalopathy than in patients with normal MRI (6 (67\%) versus 5 (50\%) versus $4(17 \%) ; P=0.01)$.

An association was found between ischemic stroke and lower platelet count, increased partial thromboplastin time (PTT), or presence of DIC. Twenty-one (37\%) patients died in the ICU, and 22 (39\%) died within 6 months from discharge (Table 2). Fourteen (67\%) patients died of septic shock-related complications, including multiple organ failure, refractory hypoxemia, and refractory hypotension. Decision to limit or withdraw life-sustaining measures was made in seven (33\%) patients; of those, four patients were in a vegetative state. At multivariate level, the presence of ischemic stroke was independently associated with ICU mortality (OR, 4.4; 95\% CI, 1.03 to $19.0 ; P=0.04)$ and GOS $>3$ at six months (OR, 6.91; 95\% CI, 1.41 to 33.65 ; $P=0.02)$.

\section{Discussion}

Our observational study shows that, in septic-shock patients with acute neurologic changes, brain MRI can reveal leukoencephalopathy or ischemic stroke, which is associated with increased ICU mortality and increased odds of having GOS > 3 at 6 months. We found that the prevalence of ischemic stroke (31\%) is higher than previously reported by Suchyta et al. (31 versus10\%, respectively) [8]. This discrepancy may be explained by the fact that in the retrospective study from Suchytha et $a l$. [8], brain imaging was obtained by means of CT scan, thus probably underestimating the rate of brain lesions.

The occurrence of ischemic stroke in sepsis patients raises questions on the role of cerebral perfusion in this population of patients. Although some studies did not show impaired perfusion [20], others indicated a decrease in cerebral perfusion pressure or in cerebral blood flow and alterations in the regulation of cerebral perfusion, including impaired $\mathrm{CO}_{2}$-reactivity and cerebrovascularpressure autoregulation [21]. It is plausible that the risk of stroke would be increased in patients with hypotension and impaired cerebral blood-flow autoregulation. The prevalence of watershed infarction suggests that hypotension might contribute to the occurrence of stroke. 

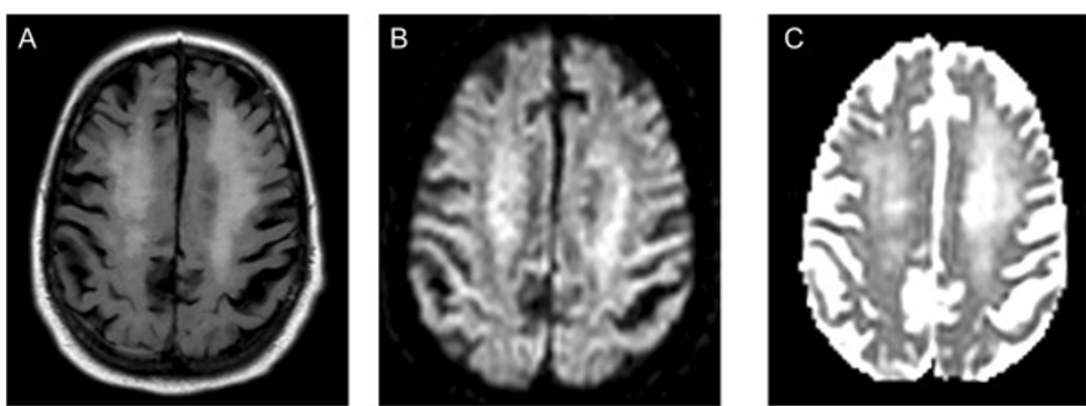

Figure 2 Severe leukoencephalopathy in a septic-shock patient in whom delirium developed. (A) Axial FLAIR at the level of the centrum semiovale, with (B) isotropic DWI map and (C) ADC map. On FLAIR images, bright and diffuse signals in the white matter extend to both hemispheres. DWI and ADC abnormalities are consistent with a vasogenic edema. ADC values measured at the level of the centrum semiovale ranged between 1.026 and $1.055 \times 10^{-3} \mathrm{~mm}^{2} / \mathrm{s}$. The patient had a Glasgow Outcome Score of 4 at 6 months.
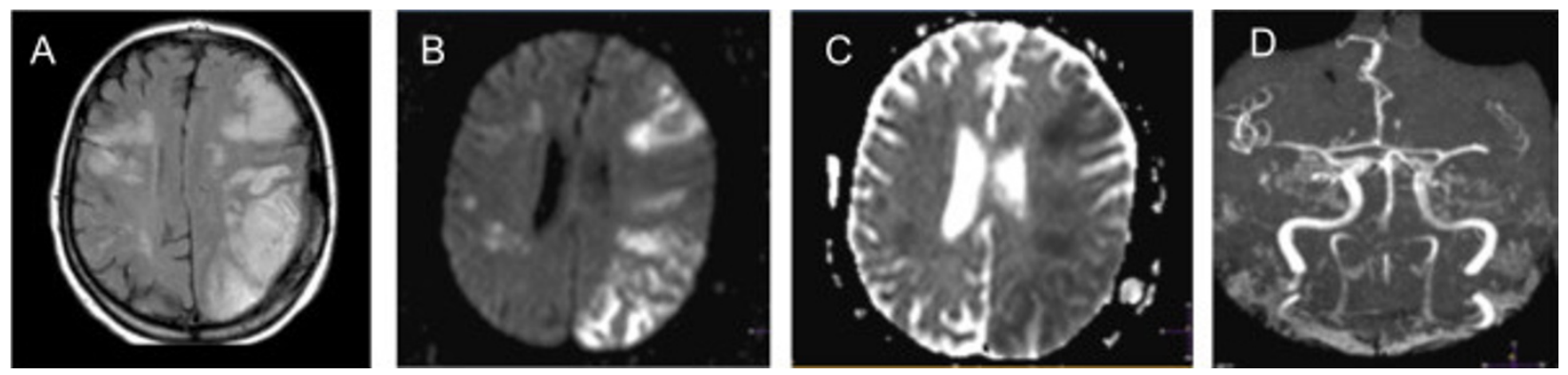

Figure 3 Multiple ischemic strokes in a septic-shock patient who remained comatose after discontinuation of sedation. Two large triangular hypersignals appear on FLAIR images (A) in the territory of the left sylvian artery and associated with DWI (B) and ADC map (C) abnormalities that are consistent with cytotoxic edema. Time of flight (TOF) (D) exhibits occlusion of left middle cerebral artery at M1 and M2 segments. Septic shock had been complicated by an intense disseminated intravascular coagulopathy. The patient died without recovering consciousness.
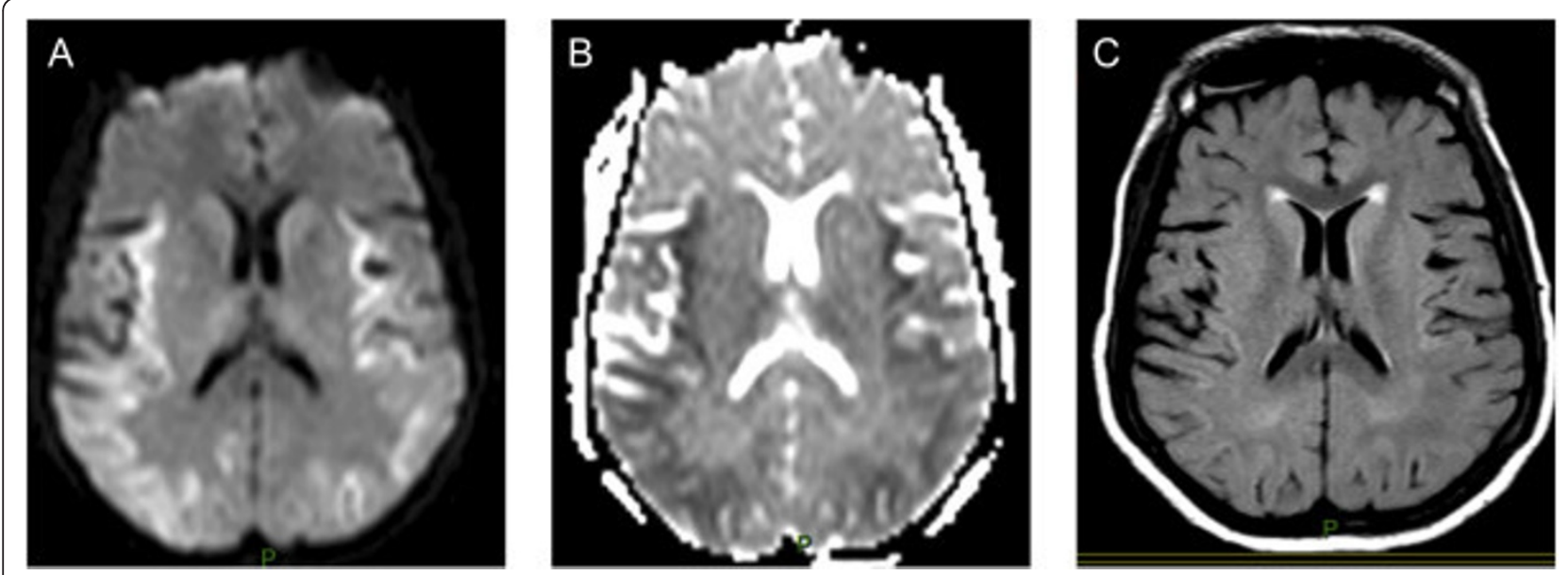

Figure 4 Diffuse and early-stage ischemia in 72-year-old septic-shock patients who developed generalized convulsive seizures without concomitant hypoxemia or hypotension. (A) DWI and the corresponding (B) ADC map show a diffuse cytotoxic edema. The absence of hypersignals on FLAIR (C) sequence shows that MRI was performed within 3 hours after the onset of ischemia. The patients died without recovering consciousness. 
Table 2 Comparison of demographic characteristics and septic-shock severity between patients with normal MRI, isolated ischemic stroke, and leukoencephalopathy

\begin{tabular}{|c|c|c|c|c|c|}
\hline & $\begin{array}{c}\text { Total } \\
63\end{array}$ & $\begin{array}{c}\text { Normal } \\
37\end{array}$ & $\begin{array}{l}\text { Leukoencephalopat hy } \\
\qquad 10\end{array}$ & $\begin{array}{l}\text { Ischemia } \\
16\end{array}$ & $P$ \\
\hline \multicolumn{6}{|l|}{ Demographics } \\
\hline Age (years) & $64(55-75)$ & $61(48-78)$ & $69(67-75)$ & $65(63-74)$ & 0.15 \\
\hline Women & $25(40)$ & $12(32)$ & $4(40)$ & $9(56)$ & 0.30 \\
\hline Cardiovascular risk factors & $37(59)$ & $19(51)$ & $8(80)$ & $10(62)$ & 0.25 \\
\hline \multicolumn{6}{|l|}{ Admission } \\
\hline SAPS ॥ & $49(38-60)$ & $52(39-60)$ & $49(31-60)$ & $48(38-55)$ & 0.79 \\
\hline \multicolumn{6}{|l|}{ Admission to MRI } \\
\hline Highest SOFA & $13(9-16)$ & $13(8-15)$ & $9(8-12)$ & $15(13-16)$ & 0.05 \\
\hline Highest CV SOFA & $3(3-4)$ & $3(3-4)$ & $2(2-3)$ & $4(3-4)$ & 0.48 \\
\hline Highest nonneuro SOFA (without GCS) & $10(7-12)$ & $10(6-12)$ & $8(5-8)$ & $11(9-12)$ & 0.16 \\
\hline Lowest MBP (mm Hg) & $52(45-55)$ & $51(45-56)$ & $53(47-63)$ & $52(41-54)$ & 0.67 \\
\hline Cumulative time with MBP $<60 \mathrm{~mm} \mathrm{Hg}$ (hours) & $6(3-8)$ & $6(3-11)$ & $2(1-7)$ & $6(5-8)$ & 0.27 \\
\hline Highest plasma PTT level & $1.8(1.4-3.2)$ & $1.4(1.7-3.2)$ & $2.0(1.3-2.2)$ & $2.5(1.6-4.2)$ & 0.06 \\
\hline Lowest plasma platelets level $\left(10^{9} / \mathrm{L}\right)$ & $97(47-224)$ & $110(51-223)^{b}$ & $228(101-351)^{c}$ & $50(23-95)$ & 0.004 \\
\hline DIC & $28(44)$ & $17(46)$ & $2(20)$ & $11(69)$ & 0.04 \\
\hline \multicolumn{6}{|l|}{ After MRI } \\
\hline Mortality & $21(33)$ & $9(24)^{b}$ & $2(20)^{c}$ & $10(62)$ & 0.02 \\
\hline GOS 6 months $\leq 3$ & $30(48)$ & $14(38)^{b}$ & $3(30)^{c}$ & $13(81)$ & 0.007 \\
\hline
\end{tabular}

Data are expressed in number (\%) or median (IQR). Kruskal-Wallis and Mann-Whitney tests were used for comparison of quantitative variables between three and two groups. ${ }^{\mathrm{a}}$ Significant difference between MRI normal and leukoencephalopathy. ${ }^{\mathrm{b}}$ Significant difference between MRI normal and ischemia. ${ }^{\mathrm{C}}$ Significant difference between MRI ischemia and leukoencephalopathy.

SAPS-II, New Simplified Acute Physiology Score; MRI, magnetic resonance imaging; SOFA, Sepsis-related Organ Failure Assessment; CV, cardiovascular; MBP, mean blood pressure; PTT, partial thromboplastin time; DIC, disseminated intravascular coagulation; GOS, Glasgow Outcome Scale.

We did not find an association between duration or severity of hypotension and cerebral ischemia in the present study or in previous neuropathologic studies [22]. However, cerebral autoregulation is altered in patients with sepsis-associated encephalopathy and would represent a better marker of cerebral hypoperfusion compared with hypotension alone [23]. Cerebral blood flow and autoregulation were not measured in our study, which was arbitrarily defined as MAP $<60 \mathrm{~mm} \mathrm{Hg}$. One way to determine the importance of cerebral perfusion in septic shock would be to determine whether perfusion monitoring and optimization reduces the prevalence of stroke. In addition to impairment of cerebral blood flow and its determinants, cerebral microcirculatory dysfunction has also been shown to be associated with brain lesions in various experimental models of sepsis but not yet in humans $[1,24]$, although it may probably be linked to diffuse ischemic damage and microhemorrhages observed in brains of patients who died of septic shock [22]. Our findings of significantly reduced platelet counts, increased PTT, and increased prevalence of DIC in patients with ischemic stroke suggest that the presence of coagulation derangement may be involved in the occurrence of brain lesions. Thrombosis of cerebral arteries has been reported in septic-shock patients with fulminant DIC [7]. Microcirculatory dysfunction and coagulopathy are both consequences of endothelial activation $[1,24]$ but are not easily preventable or treatable.

We found that a cardioembolic (essentially atrial fibrillation) or thromboembolic factor was present in $70 \%$ of patients with ischemic stroke. Interestingly, it was very recently shown that new-onset atrial fibrillation is associated with increased prevalence of stroke and mortality in sepsis patients [25]. Thus, our results suggest that ischemic stroke in sepsis patients can be favored by previous predisposing factors, result from sepsis-related particular conditions (DIC, microcirculatory alterations, and so on), or both..

Another consequence of endothelial activation is the failure of the blood-brain barrier (BBB), leading to the passage of inflammatory mediators and neurotoxic factors into the brain [1]. We hypothesized that leukoencephalopathy reflects $\mathrm{BBB}$ alteration, originating within the Virchow-Robin spaces and potentially propagating to other brain structures [7]. An alteration of BBB was identified neuropathologically in a patient with a diffuse leukoencephalopathy [7]. The present study confirmed that severe leukoencephalopathy is the second most frequent brain lesions (21\%). We did not find a significant association between leukoencephalopathy and any specific acute neurological sign. The fact that comparable white matter lesions have not been reported in nonsepsis critically ill 
Table 3 Comparison of neurologic and electroencephalographic features between patients with normal MRI, isolated leukoencephalopathy, and isolated ischemic stroke

\begin{tabular}{|c|c|c|c|c|c|}
\hline \multirow{2}{*}{$\begin{array}{l}\text { Clinical } \\
\text { features }\end{array}$} & \multirow{2}{*}{$\begin{array}{c}\text { Total } \\
63 \\
\end{array}$} & \multirow{2}{*}{$\begin{array}{c}\text { Normal } \\
37\end{array}$} & \multirow{2}{*}{$\begin{array}{l}\text { Leukoencephalopathy } \\
\qquad 10 \\
\end{array}$} & \multirow{2}{*}{$\begin{array}{c}\text { Ischemia } \\
16 \\
\end{array}$} & \multirow[t]{2}{*}{$P$} \\
\hline & & & & & \\
\hline $\begin{array}{l}\text { GCS motor } \\
\text { response }\end{array}$ & $\begin{array}{c}4(1- \\
6)\end{array}$ & $4(1-6)$ & $5(4-6)$ & $3(1-4)$ & 0.21 \\
\hline \multicolumn{6}{|l|}{$\begin{array}{l}\text { Neurologic } \\
\text { symptoms }\end{array}$} \\
\hline $\begin{array}{l}\text { Focal } \\
\text { neurologic } \\
\text { signs }\end{array}$ & $\begin{array}{c}11 \\
(17)\end{array}$ & $2(5)^{b}$ & $1(10)^{c}$ & $8(50)^{b, c}$ & 0.004 \\
\hline Coma & $\begin{array}{c}31 \\
(41)\end{array}$ & $17(46)$ & $2(20)$ & $10(62)$ & 0.11 \\
\hline Seizure & $\begin{array}{c}6 \\
(10)\end{array}$ & $4(11)$ & $0(0)$ & $2(12)$ & 0.53 \\
\hline Delirium & $\begin{array}{c}31 \\
(49)\end{array}$ & $19(51)$ & $7(70)$ & $5(31)$ & 0.15 \\
\hline \multirow[t]{2}{*}{ EEG findings } & Total & Normal & Leukoencephalopathy & Ischemia & $P$ \\
\hline & 43 & 24 & 10 & 9 & \\
\hline $\begin{array}{l}\text { Electrographic } \\
\text { seizure }\end{array}$ & $\begin{array}{c}13 \\
(30)\end{array}$ & $9(38)$ & $2(20)$ & $2(22)$ & 0.50 \\
\hline Slow waves & $\begin{array}{c}5 \\
(11)\end{array}$ & $4(11)$ & $0(0)$ & $1(11)$ & 0.38 \\
\hline $\begin{array}{l}\text { Three-phasic } \\
\text { waves }\end{array}$ & $5(8)$ & $1(4)$ & $2(20)$ & $2(22)$ & 0.63 \\
\hline $\begin{array}{l}\text { Synek } \\
\text { classification }\end{array}$ & $\begin{array}{l}3(1- \\
4)\end{array}$ & $3(1-4)$ & $2(1-4)$ & $4(1-4)$ & 0.06 \\
\hline EEG grade $>3$ & $\begin{array}{l}15 \\
(35)\end{array}$ & $4(17)$ & $5(50)^{a}$ & $6(67)^{b}$ & 0.01 \\
\hline
\end{tabular}

An EEG was performed in 47 patients who developed coma, delirium, or both Among these 47 patients, four had mixed brain lesions and were excluded from the comparison analysis.

Data are expressed in number (\%) or median (IQR). Kruskal-Wallis and MannWhitney test were used for comparison of quantitative variables between

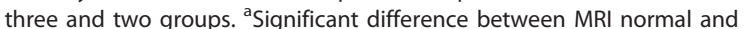
leukoencephalopathy. 'bignificant difference between MRI normal and ischemia. 'Significant difference between MRI ischemia and leukoencephalopathy.

GCS, Glasgow Coma Scale; EEG, electroencephalogram.

patients [8] is consistent with an inflammatory process. However, this pathophysiological hypothesis is not supported by our findings, as the severity of septic shock and other biologic markers of inflammation or endothelial activation did not correlate with leukoencephalopathy. That we could not find any significant association between the presence of leukoencephalopathy and severity of illness and markers of inflammation may be due to the small number of this subgroup of patients rather than a true lack of association. Moreover, we limited our analyses to conventional clinical biomarkers of inflammation and endothelial activation. More-sophisticated analysis, including plasma cytokines and adhesion molecules levels, will be warranted for future studies.

Finally, we found that the MRI was normal in 52\% of our cohort of patients. Our results are consistent with those obtained by Suchyta et al. [8] in critically ill patients. The risk stratification of MRI lesions in sepsis patients might be based on the electroencephalographic pattern. Indeed, we found that malignant EEG pattern, as defined in Synek's classification, is correlated with the presence of ischemic stroke or leukoencephalopathy on MRI in comatose or delirious patients. This result suggests that EEG should be done and before MRI.

The current study has several limitations. This observational study investigated the prevalence of neuroradiologic lesions in a very selected patient population with septic shock with acute neurological symptoms, without contraindication to MRI and preexisting cerebral disease. Forty patients died before MRI could be performed. It is possible that those patients would have shown more-severe brain lesions, as suggested by postmortem neuropathologic studies [22]. The prevalence and type of brain lesion in asymptomatic patients or in those with more-subtle brain dysfunction was not analyzed. However, neuroradiologic assessment of these patients would raise some ethical issues related mainly to the risks of transporting potentially unstable patients 38 with no neurologic signs to MRI, unless neuroimaging were performed at the time of recovery from septic shock. It has been shown that patients with sepsis are at high risk of developing long-term cognitive disability [5] and that cognitive impairment is more frequent in critically ill patients with abnormal brain imaging $[8,26,27]$. We are not able to determine either the time-to-recovery of a normal neurologic examination or the relations between neuroimaging and long-term cognitive function. Prevalence of coma, delirium, and convulsive seizures in our cohort is consistent with the prevalence previously reported in the literature [6]. Furthermore, the use of MRI with higher field strength, use of spectroscopy, and use of diffusion tensor imaging might have allowed detection of smaller ischemic lesions or other anatomic or neurochemical abnormalities.

A larger cohort of patients would allow a more accurate estimation of the prevalence of each type of brain lesion and the respective risk factors. Yet available MRI studies in septic-shock patients are scant, often retrospective, single center, and have included fewer than 10 cases $[7,8]$, indicating the difficulties of performing such an exploration in sepsis patients. The occurrence of focal neurologic signs, delirium, or coma, as well as prevalence of ischemic stroke and leukoencephalopathy, remained steady over the study period. No significant change in monitoring and treatment of patients with septic shock was found in our ICU during the study period. Larger multicenter studies with the standardization of both clinical and imaging protocols across centers are needed.

Finally, it is conceivable that the use of continuous or daily standard EEG would have enabled to us to detect 
more accurately sepsis-associated encephalopathy or nonconvulsive seizures [6].

\section{Conclusion}

The present study showed that the MRI is abnormal in half of septic-shock patients who developed acute brain dysfunction. Our data also showed that ischemic stroke and leukoencephalopathy are the two most frequent lesions in sepsis patients and that ischemia is associated with increased mortality and mid-term neurologic disability, defined as GOS $>3$. Larger multicenter cohort studies are warranted to elucidate the potential benefit of strategies aimed at manipulating both cerebral perfusion and coagulation in patients with septic shock.

\section{Key messages}

1. MRI can reveal leukoencephalopathy or ischemic stroke in septic-shock patients with acute brain dysfunction.

2. Ischemic stroke is associated with increased mortality, mid-term neurologic disability, and biological DIC.

3. Severity and type of neuroradiologic lesions correlate with EEG alterations.

\begin{abstract}
Abbreviations
ADC: apparent diffusion coefficient; ATICE: adaptation to the intensive care environment; BBB: blood-brain barrier; CAM-ICU: confusion assessment method for the ICU; DIC: disseminated intravascular coagulation; DWI: diffusion-weighted imaging; ECG: electrocardiogram; EEG: electroencephalography; EPI: echo-planar imaging; FLAIR: fluid-attenuated inversion recovery; GCS: Glasgow Coma Scale; GOS: Glasgow Outcome Scale; ICU: intensive care unit; MBP: mean blood pressure; MRI: magnetic resonance imaging; MTC: magnetization transfer contrast; PT: prothrombin time; PTT: partial thromboplastin time; RASS: Richmond Agitation Sedation Scale; $\mathrm{SaO}_{2}$ : oxygen saturation; SAPS II: New Simplified Acute Physiology Score; SOFA: Sequential Organ Failure Assessment.
\end{abstract}

\section{Competing interests}

The authors declare that they have no competing interests.

\section{Authors' contributions}

AndP conceived of the study, helped acquire data, and wrote the manuscript. FE, aided in acquisition of data. ALM, acquired data. AngP performed the statistical analysis and helped to draft the manuscript. EA, acquired data. DA, helped in interpretation of data. FC helped in interpretation of data. RS conceived of the study and helped to revise the manuscript. RC participated in coordination of the study and the acquisition and interpretation of data. TS conceived of the study and wrote the manuscript.

All authors read and approved the final manuscript.

\section{Acknowledgements}

This research received no grant from any funding agency in the public, commercial, or not-for-profit sectors.

\section{Authors' details}

${ }^{1}$ General Intensive Care Medicine, Assistance Publique Hôpitaux de Paris, Boulevard Raymond Poincaré Hospital, University of Versailles Saint-Quentin en Yvelines, Raymond Poincaré 104, Garches, 92380, France. ${ }^{2}$ Department of Radiology, Assistance Publique Hôpitaux de Paris, Boulevard Raymond Poincaré Hospital, University of Versailles Saint-Quentin en Yvelines, Raymond Poincaré 104, Garches, 92380, France. ${ }^{3}$ Cardiac Intensive Care Unit, Bambino Gesú Children's Hospital, IRCCS, Piazza Sant'Onofrio 4, Rome, 00165, Italy. ${ }^{4}$ Department of Physiology, Assistance Publique Hôpitaux de Paris,
Boulevard Raymond Poincaré Hospital, University of Versailles Saint-Quentin en Yvelines, Raymond Poincaré 104, Garches, 92380, France. ${ }^{5}$ Unit: Histopathology and Animal Models, Institut Pasteur; and Sainte Anne Hospital, University of Paris Descartes, Rue du Docteur Roux 25-28, Paris, 75015, France. ${ }^{6}$ Departments of Anesthesiology and Critical Care Medicine, Neurology; and Neurosurgery, Johns Hopkins University School of Medicine, 600 North Wolfe St, Meyer 8-140, Baltimore, MD, USA.

Received: 7 December 2012 Revised: 13 January 2013

Accepted: 18 September 2013 Published: 18 September 2013

\section{References}

1. lacobone E, Bailly-Salin J, Polito A, Friedman D, Stevens RD, Sharshar T: Sepsis-associated encephalopathy and its differential diagnosis. Crit Care Med 2009, 37:S331-336.

2. Sprung CL, Peduzzi PN, Shatney $C H$, Schein RM, Wilson MF, Sheagren JN, Hinshaw LB: Impact of encephalopathy on mortality in the sepsis syndrome: The Veterans Administration Systemic Sepsis Cooperative Study Group. Crit Care Med 1990, 18:801-806.

3. Eidelman LA, Putterman D, Putterman C, Sprung CL: The spectrum of septic encephalopathy: definitions, etiologies, and mortalities. JAMA 1996, 275:470-473.

4. Girard TD, Jackson JC, Pandharipande PP, Pun BT, Thompson JL, Shintani AK, Gordon SM, Canonico AE, Dittus RS, Bernard GR, Ely EW: Delirium as a predictor of long-term cognitive impairment in survivors of critical illness. Crit Care Med 2010, 38:1513-1520.

5. Iwashyna TJ, Ely EW, Smith DM, Langa KM: Long-term cognitive impairment and functional disability among survivors of severe sepsis. JAMA 2010, 304:1787-1794.

6. Oddo M, Carrera E, Claassen J, Mayer SA, Hirsch LJ: Continuous electroencephalography in the medical intensive care unit. Crit Care Med 2009, 37:2051-2056.

7. Sharshar T, Carlier R, Bernard F, Guidoux C, Brouland JP, Nardi O, de la Grandmaison GL, Aboab J, Gray F, Menon D, Annane D: Brain lesions in septic shock: a magnetic resonance imaging study. Intensive Care Med 2007, 33:798-806.

8. Suchyta MR, Jephson A, Hopkins RO: Neurologic changes during critical illness: brain imaging findings and neurobehavioral outcomes. Brain Imaging Behav 2010, 4:22-34.

9. Dellinger RP, Levy MM, Carlet JM, Bion J, Parker MM, Jaeschke R, Reinhart K, Angus DC, Brun-Buisson C, Beale R, Calandra T, Dhainaut JF, Gerlach H, Harvey M, Marini JJ, Marshall J, Ranieri M, Ramsay G, Sevransky J, Thompson BT, Townsend S, Vender JS, Zimmerman JL, Vincent JL: Surviving Sepsis Campaign: international guidelines for management of severe sepsis and septic shock: 2008. Crit Care Med 2008, 36:296-327.

10. Siami S, Bailly-Salin J, Polito A, Porcher R, Blanchard A, Haymann JP, Laborde K, Maxime V, Boucly C, Carlier R, Annane D, Sharshar T: Osmoregulation of vasopressin secretion is altered in the postacute phase of septic shock. Crit Care Med 2010, 38:1962-1969.

11. Sonneville R, Mirabel M, Hajage D, Tubach F, Vignon P, Perez P, Lavoue S, Kouatchet A, Pajot O, Mekontso Dessap A, Tonnelier JM, Bollaert PE, Frat JP, Navellou JC, Hyvernat H, Hssain AA, Tabah A, Trouillet JL, Wolff M: Neurologic complications and outcomes of infective endocarditis in critically ill patients: the ENDOcardite en REAnimation prospective multicenter study. Crit Care Med 2011, 39:1474-1481.

12. De Jonghe B, Cook D, Griffith L, Appere-de-Vecchi C, Guyatt G, Theron V, Vagnerre A, Outin H: Adaptation to the Intensive Care Environment (ATICE): development and validation of a new sedation assessment instrument. Crit Care Med 2003, 31:2344-2354.

13. Sessler CN, Gosnell MS, Grap MJ, Brophy GM, O'Neal PV, Keane KA, Tesoro EP, Elswick RK: The Richmond Agitation-Sedation Scale: validity and reliability in adult intensive care unit patients. Am J Respir Crit Care Med 2002, 166:1338-1344.

14. Ely EW, Inouye SK, Bernard GR, Gordon S, Francis J, May L, Truman B, Speroff T, Gautam S, Margolin R, Hart RP, Dittus R: Delirium in mechanically ventilated patients: validity and reliability of the confusion assessment method for the intensive care unit (CAM-ICU). JAMA 2001, 286:2703-2710.

15. Sharshar T, Porcher R, Siami S, Rohaut B, Bailly-Salin J, Hopkinson NS, Clair B, Guidoux C, lacobone E, Sonneville R, Polito A, Aboab J, Gaudry S, Morla O, Amouyal G, Azuar J, Allary J, Vieillard-Baron A, Wolff M, Cariou A, Annane D: 
Brainstem responses can predict death and delirium in sedated patients in intensive care unit. Crit Care Med 2011, 39:1960-1967.

16. Adams HP Jr, Bendixen BH, Kappelle L, Biller J, Love BB, Gordon DL, Marsh EE: Classification of subtype of acute ischemic stroke: definitions for use in a multicenter clinical trial: TOAST, Trial of Org 10172 in Acute Stroke Treatment. Stroke 1993, 24:35-41.

17. Synek VM: Prognostically important EEG coma patterns in diffuse anoxic and traumatic encephalopathies in adults. J Clin Neurophysiol 1988, 5:161-174.

18. Taylor FB Jr, Toh CH, Hoots WK, Wada H, Levi M: Towards definition, clinical and laboratory criteria, and a scoring system for disseminated intravascular coagulation. Thromb Haemost 2001, 86:1327-1330.

19. Jennett $\mathrm{B}$, Bond $\mathrm{M}$ : Assessment of outcome after severe brain damage. Lancet 1975, 1:480-484.

20. Matta BF, Stow PJ: Sepsis-induced vasoparalysis does not involve the cerebral vasculature: indirect evidence from autoregulation and carbon dioxide reactivity studies. Br J Anaesth 1996, 76:790-794.

21. Burkhart CS, Siegemund M, Steiner LA: Cerebral perfusion in sepsis. Crit Care 2010, 14:215.

22. Sharshar T, Annane D, de la Grandmaison GL, Brouland JP, Hopkinson NS, Francoise G: The neuropathology of septic shock. Brain Pathol 2004, 14:21-33.

23. Pfister D, Siegemund M, Dell-Kuster S, Smielewski P, Ruegg S, Strebel SP Marsch SC, Pargger H, Steiner LA: Cerebral perfusion in sepsis-associated delirium. Crit Care 2008, 12:R63.

24. Taccone FS, Su F, Pierrakos C, He X, James S, Dewitte O, Vincent JL, De Backer D: Cerebral microcirculation is impaired during sepsis: an experimental study. Crit Care 2010, 14:R140.

25. Walkey AJ, Wiener RS, Ghobrial JM, Curtis LH, Benjamin EJ: Incident stroke and mortality associated with new-onset atrial fibrillation in patients hospitalized with severe sepsis. JAMA 2011, 306:2248-2254.

26. Lee JY, Insel P, Mackin RS, Schuff N, Chui H, Decarli C, Park KH, Mueller SG, Weiner MW: Different associations of white matter lesions with depression and cognition. BMC Neurol 2012, 12:83.

27. Morandi A, Gunther ML, Vasilevskis EE, Girard TD, Hopkins RO, Jackson JC, Pandharipande P, Ely EW: Neuroimaging in delirious intensive care unit patients: a preliminary case series report. Psychiatry (Edgmont) 2010, 7:28-33

doi:10.1186/cc12899

Cite this article as: Polito et al: Pattern of Brain Injury in the Acute

Setting of Human Septic Shock. Critical Care 2013 17:R204.

\section{Submit your next manuscript to BioMed Central and take full advantage of:}

- Convenient online submission

- Thorough peer review

- No space constraints or color figure charges

- Immediate publication on acceptance

- Inclusion in PubMed, CAS, Scopus and Google Scholar

- Research which is freely available for redistribution

Submit your manuscript at www.biomedcentral.com/submit
Biomed Central 